\title{
The British Stock Market under the Structure of Market Capitalization Value: New Evidence on its Predictive Content
}

\section{Catherine Georgiou ${ }^{\dagger}$}

Business Division, Department of Economics, Aristotle University of Thessaloniki, 54124, Thessaloniki, Greece

\begin{tabular}{l}
\hline ARTICLE INFO \\
\hline Article History \\
Received 13 September 2020; \\
Accepted 4 January 2020 \\
\hline JEL Classifications \\
G11, G12, G17, E44
\end{tabular}

Keywords:

Return predictability, dividend growth, earnings growth, size portfolios, FTSE 100 \begin{abstract} Purpose:

The aim of our paper is twofold. First, we examine the predictive ability of log bookmarket, dividend-price, earnings-price and dividend-earnings ratios on the most recent data set of the strongest securities in the UK economy; unlike the majority of the studies in this data set, our analysis is not limited on returns but further investigates dividend and earnings growth predictability under the presence of the most recent global financial recession. Second, we exploit the long-run equilibrium relationship in two systems, $\left[p_{t}, d_{t}, e_{t}\right]$ and $\left[p_{t}, b_{t}, e_{t}\right]$ and examine the predictive ability of our newly formed variables, namely $p d e_{t}$ and $p b e_{t}$.
\end{abstract}

Design/methodology/approach:

In this study, we examine the most recent data set of Financial Times Stock Exchange 100 (FTSE 100) and analyze it based on the formation of size portfolios. The main focus is placed on the index's returns, dividend and earnings growth rates and the predictive ability of the four financial ratios we have selected following their reputation as strong predictors. We also formulate two extra ratios based on their long-run equilibrium relationship.

Finding:

Our study's main findings can be summarized as following. First, we retrieve evidence that in-sample return predictability is evident in the medium and large-sized portfolios and is better captured by $p d e_{t}$ at $35 \%$ and $47 \%$ equivalently. Second, forecasts on dividend growth are even more linked to the size criterion we employ. Third, in-sample regressions of continuously compounded earnings growth rate show that most predictive benefits are obtained by $d p_{t}$ in the medium portfolio with an $R^{2}$ of $45 \%$.

Research limitations/implications:

A first constraint is the forecasters we employ; we have used the most indicative ones due to their popularity in similar data sets but there are other macroeconomic variables such as spreads and interest rates that could be tested in future research. Also, we could examine the sensitivity of our results on whether we use nominal, excess or real returns and then, attempt to alter our data's frequency so as to address the seasonality effect observed mainly in dividends and earnings.

Originality/value:

We believe that our paper contributes to the ongoing debate of the traits that make return predictable and the information included in either dividends or earnings to explain that predictability. Finally, the novelty of this paper lies in the links it tries to retrieve among market capitalization value and predictability in a market whose predictive components have not been entirely explored. Our paper may prove informative to investors focused on short-term forecasting and interested in the effects of size in portfolio formation.

\section{Introduction}

There have been intensive efforts on examining the predictive ability of certain macroeconomic variables so as to produce valid forecasts. Employing a number of data sets and methodologies, the empirical literature has covered in great depth the issues of financial ratios' ability to explain variations in stock returns and shed light on other predictable components such as dividend and earnings (see for example, Cochrane, 2009; Lettau and Ludvigson, 2005; Campbell and Shiller, 2001). A significant limitation of the literature though is that it has primarily focused on US

${ }^{\dagger}$ Corresponding author: Catherine Georgiou

e-mail: ageorgiou@econ.auth.gr 
data (see, e.g. Campbell and Shiller, 2001; Cochrane, 2009; Lettau and Ludvigson, 2001; Welch and Goyal, 2008 ; Ang and Bekaert, 2007). Fewer studies can be retrieved with regards to European data, and in particular UK data sets (e.g. Fletcher, 2010; Clare et al., 1997; Michou et al., 2012) with the notable exception of a rather small number of studies which have focused on the ability of several forecasters to predict UK stock returns (see Strong et al., 1997; Morelli, 2007).

Under the light of this event, our paper tries not only to retrieve evidence of returns forecasting in the British market, but it also associates the findings with market capitalization value by fixing size portfolios of the market's strongest index. We therefore focus on the Financial Times Stock Exchange 100 (FTSE 100) and group its securities into size portfolios of returns, dividend and earnings growth. The included securities are grouped in such a way that the small portfolio consists of one third of the index's securities with the smallest market capitalization value, while the large portfolio includes the last third of FTSE 100 with the highest market cap value. Consequently, we construct three (small, medium and large) return portfolios, and extend our analysis by also fixing three dividend and three earnings growth portfolios. There are three main reasons why the UK market is chosen as a case study in this research; first, the data availability and second, the quality of the data are far more superior compared to other markets. Third, since the research efforts on US datasets are so extensive, it is perhaps more efficient in terms of comparison to isolate the Anglo-Saxon economies and study similarities, if any, in forecasting patterns.

We examine the predictive power of book-price $\left(b p_{t}\right)$, dividend-price $\left(d p_{t}\right)$, earnings-price $\left(e p_{t}\right)$ and dividendearnings' $\left(d e_{t}\right)$. Unlike the majority of the studies in this field, our forecasts are only in-sample, since due to data availability, we are unable to provide out-of-sample forecasts. However, we leave this puzzle for future research. The selection of the ratios is primarily based on these ratios' predictive capacity in return forecasting as they are all wellrenowned for their predictive benefits (Lamont, 1998; Cochrane, 1999b; Torous et al., 2004). Specifically, Pontiff and Schall (1998) argue that $b p_{t}$ acts a good predictor because book value proxies for expected future cash flows, while in $d p_{t}$ 's case, there has been a vigorous discussion over dividend's ability to measure the permanent components of stock prices, and thus explain the managerial behavior behind dividend policies setting (Cochrane, 2009). Regarding $e p_{t}$ 's predictive ability, it is linked to its potential to be a good measure of current business conditions (Lamont, 1998), while the classical $d e_{t}$ ratio has provoked fruitful discussion and empirical research since it associates the level of future earnings to dividend payment schemes (Gill et al., 2010).

In this context the aim of our paper is twofold. First, we examine the predictive ability of $\log b p_{t}, d p_{t}, e p_{t}$ and $d e_{t}$ ratios on the most recent data set of the strongest securities in the UK economy; unlike the majority of the studies in this data set, our analysis is not limited on returns but further investigates dividend and earnings growth predictive patterns under the presence of the most recent global financial recession. Previous research on this specific dataset indicates rather mild evidence of returns predictability by ratios such as the dividend and earnings yields (see Morelli, 2007), while classical performance models such as the CAPM and Fama and French factor models are unable to interpret observed variations in the British stock market (see Fletcher, 2001; Georgiou et al., 2019). We also exploit the long-run equilibrium relationship in two systems, $\left[p_{t}, d_{t}, e_{t}\right]$ and $\left[p_{t}, b_{t}, e_{t}\right]$ and examine the predictive ability of our newly formed variables, namely $p d e_{t}$ and $p b e_{t}$. Similar efforts may have been employed before primarily on US data, however the degree at which cointegrated series can forecast the UK returns remains unexplored.

We believe that our paper contributes to the ongoing debate of the traits that make return predictable and the information included in either dividends or earnings to explain that predictability. Finally, the novelty of this paper lies in the links it tries to retrieve among market capitalization value and predictability in a market whose predictive components have not been entirely explored. This study presents new evidence with regards to the strongest index of the UK economy during a severe economic recession worldwide. To the best of our knowledge such an analysis with this specific data set has not been reported elsewhere.

The remainder of the paper is organized as follows: Section 2 presents some key references of the literature review on time series predictability, while Section 3 sets our research framework. Section 4 formally examines the ability of our selected financial ratios to forecast the UK returns, dividend and earnings growth rates in-sample. Concluding remarks follow in Section 5.

\section{Literature Review}

\subsection{Evidence of ratios that predict returns}

The literature that examines return predictability has extensively referred to several variables that potentially explain the observed variations in returns. With regards to the ratios employed in this study, there have been vigorous theoretical and empirical discussions stressing that both $d p_{t}$ (see the discussion in Campbell and Viceira, 2002; Lewellen, 2004; Campbell and Yogo, 2006) and $e p_{t}$ (e.g. Campbell and Shiller, 1998; Lamont, 1998; Shen, 2000) are highly persistent, and that is the reason why predictability as measured by $R^{2}$, tends to rise in longer horizons. For instance, Lewellen (2004) reports that both $d p_{t}$ and $e p_{t}$ 's persistence is strong, leading to a coefficient of 0.99 on a monthly basis during the period 1946-2000. Campbell and Yogo (2006) show that $e p_{t}$ 's predictive benefits are stronger in US data, while $d p_{t}$ can predict returns but only on an annual basis. On the other hand, by examining similar ratios' forecasting ability on a variety of data sets, Campbell and Shiller (2001) conclude that $d p_{t}$ and $e p_{t}$ are weak forecasters of dividend and earnings growth, but they do forecast changes in future stock prices. Shen (2000) reports that high pe ratios today mean low stock prices tomorrow. 
Supplementary studies on the selected forecasters include Lamont (1998) who examines dividends and earnings ability to predict returns during 1947-1994 and argues that financial ratios are rather weak in long-term predictions but do a fine job on the short-term. He argues that the reason why de $e_{t}$ provides evidence of predictability is either because dividends can predict future returns and/or earnings do. More specifically, he supports that dividends measure the managerial behavior in dividends setting schemes, thus dividends is a good measure of the permanent component in prices. On the other hand, earnings vary according to the economic conditions; in times of recession, investors demand high expected returns, while in times of booms, they do not worry on lower expected returns. In other words, earnings is a good measure of the current business conditions. Finally, when examining the ability of $b p_{t}$ to similarly explain variations in the stock market, Pontiff and Schall (1998) associate its predictive ability to size portfolios and argue that it is a far stronger predictor compared to other examined variables such as dividend yields and interest rate spreads; in fact, it manages to predict both future market returns and excess returns of DJIA and S\&P stocks in small portfolios for the period 1920-1993. Cochrane (1999) also supports that low price-book values today signal high average returns tomorrow; it is the value of prices rather than the book values that determines future returns in either individual or grouped into size-portfolios securities and thus, book values alone hold almost minor predictive power (Berk, 1995; Cochrane, 1999).

More specifically about the UK market, variables that have been identified for their strong predictive benefits are the $d p_{t}$ ratio, the January effect ${ }^{1}$, money supply, inflation rate and the company size effect. Li (2009) argues that out of these variables, the January effect is the most powerful predictor. Also, Bowen et al. (2010) report predictability evidence on the UK market, identifying certain periods that are highly predictable. By employing the Lo and MacKinlay Variance Ratio and the Chow and Denning Multiple Variance Ratio, they form size portfolios similar to the ones of this study for the period 1963-2007. They argue that in certain sub-periods, namely 1965-1974 and 19751985, all size portfolios are predictable, while during 1986-1996 only the large size portfolios have some predictive benefits. Their paper also examines the 1997-2007 period, during which predictability is revived for the majority of the included stocks in their sample.

\subsection{Dividend growth predictive evidence}

A separate strand of empirical literature is also focused on the dividend growth predictability (Ang and Bekaert, 2007; Welch and Goyal, 2008; Lettau and Van Nieuwerburgh, 2008; Cochrane, 2009) and mainly stresses on $d p_{t}$ 's forecasting ability. Cochrane (2009) argues that $d p_{t}$ is unable to predict dividend growth on US data, and $d p_{t}$ 's variations can only explain expected returns' variations. A similar result is also retrieved for the UK data set by Wetherilt and Wells (2004), who run the same regression as Cochrane on non-overlapping data for the period 19252002 and receive an $R^{2}$ equal to 0.02 compared to Cochrane's result at 0.06 . Nonetheless, they do find evidence of UK predictability on quarterly excess returns, confirming that both $d p_{t}$ and $e p_{t}$ have some predictive power.

A more recent study of Garrett and Priestley (2012) on a similar data set, presents evidence that dividend growth is indeed highly predictable when the predictor variable is estimated from the cointegration relationship between dividends, prices and earnings. Retrieving evidence on cointegrated time series and testing whether these long-run equilibrium relationships can explain variations in different stock markets has been employed before. For example, Lettau and Ludvigson (2001) fix their consumption-wealth ratio (cay) in US data sets and further elaborate on the reasons why the traditional $d p_{t}$ ratio is a weak forecaster of dividend growth and why their cay interprets business cycle variations in expected excess returns.

\subsection{Earnings growth predictability}

Finally, references on earnings growth predictability are rather limited, particularly in the British data. In fact, earnings growth has been associated with return predictability either in cross-sectional or time series studies (see for example, Teets and Wasley, 1996; Kothari et al., 2006). Campbell (1991) argues that there are two scenarios for earning changes at time t; either they are positively correlated with news of expected returns at time t, or/and they are negatively correlated with expected returns at time $\mathrm{t}-1$. An indicative study on monthly and annual US returns for instance, for the period 1965-2005, report that the $d p_{t}$ ratio is able to predict earnings growth and returns but in opposite directions (that is, high $d p_{t}$ values predict higher returns and lower earnings growth rates), indicating that both expected returns and expected earnings are negatively correlated (Sadka and Sadka, 2009). A supplementary reason why researchers are rather reluctant on employing earnings data in financial forecasting may also be the very nature of the data sets; the variety of accounting definitions and the changing measurement traits of earnings produce earnings related ratios that may seriously tackle with their forecastability. An indicative example is Siegel's recent paper (2016) who fixes Campbell and Shiller's cyclically-adjusted price-earnings ratio (cape) with either NIPA profits and S\&P's reported earnings; he shows that cape constructed by NIPA data is a stronger forecaster.

\footnotetext{
${ }^{1}$ A seasonal effect, suggesting that January average returns are much higher compared to other months (see the discussion in Clare et al., 1995).
} 


\section{Research Methodology}

\subsection{Data description}

Our data set consists of monthly observations on prices, $e p_{t}, b p_{t}$ and $d e_{t}$ of each stock included in the Financial Times Stock Exchange 100 (FTSE 100), covering the period 1996:01-2016:12. We construct three size portfolios, based on stocks' market capitalization value. Therefore, the "small" portfolio consists of one third of the securities with the lowest market capitalization value of the index, while the "large" portfolio includes the last third of the securities with the highest market cap value. There are two primary arguments in favor of sorting stocks in portfolios; first, it reduces the idiosyncratic volatility, and second, factor loadings and thus, risk premia are more precisely estimated. This is an approach which originates in Blume (1970) who argues that the estimation errors in betas can be scattered away when stocks are aggregated in portfolios. The main rationale is that the more precision we receive when estimating factor loadings, the more precise we can be overall and have lower standard errors of factor risk premia (see the discussion in Black, Jensen and Scholes, 1972; Fama and MacBeth, 1973; Fama and French, 1993).

With regards to our dependent variables, we construct returns $\left(r_{t}\right)$, dividend growth $\left(\Delta d_{t}\right)$ and earnings growth $\left(\Delta e_{t}\right)$ of all size portfolios on a monthly basis. We denote $r_{t}$ as the log nominal returns of each portfolio, $P_{t}, D_{t}, B_{t}$ and $E_{t}$ the values of price, dividends, book and earnings at month $t$, respectively. When lowercase numbers are used, they stand for the $\log$ values of their capital equivalents (that is, $p_{t}=\log P_{t}, d_{t}=\log D_{t}, b_{t}=\log B_{t}$ and $e_{t}=\log E_{t}$ ). The monthly returns are estimated following the formula:

$$
r_{t}=\log \left(\frac{P_{t}+D_{t}}{P_{t-1}}\right)
$$

This estimation is similar to the rationale of Ang and Bekaert (2007) and Chen (2009).

By keeping size as our selection criterion of grouping the total 100 stocks included in the index, we additionally form three dividend and three earnings growth portfolios. Overall, nine portfolios (three return portfolios, three dividend and three earnings growth portfolios) are constructed in this study.

The monthly dividend growth rate is estimated as,

$$
\Delta d_{t}=\log \left(\frac{D_{t+1}}{D_{t}}\right)=\log \left(\frac{\left(\frac{D_{t+1}}{P_{t+1}}\right)}{\left(\frac{D_{t}}{P_{t}}\right)} \frac{P_{t+1}}{P_{t}}\right)=\log \left(\frac{D_{t+1}}{P_{t+1}} \frac{P_{t}}{D_{t}} \frac{P_{t+1}}{P_{t}}\right),
$$

where, $\frac{P_{t+1}}{P_{t}}$ is the monthly returns without dividends. The monthly earnings growth rate is respectively,

$$
\Delta e_{t}=\log \left(\frac{E_{t+1}}{E_{t}}\right)=\log \left(\frac{\left(\frac{E_{t+1}}{P_{t+1}}\right)}{\left(E_{t} / P_{t}\right)} \frac{P_{t+1}}{P_{t}}\right)=\log \left(\frac{E_{t+1}}{P_{t+1}} \frac{P_{t}}{E_{t}} \frac{P_{t+1}}{P_{t}}\right)
$$

These variables are constructed under the rationale of Cochrane (2009).

The synthesis of our independent variables includes $b p_{t}$ estimated as the ratio of book value to price for each security, as calculated by Bloomberg database. We consider dividends as the 12-month moving sums of dividends paid on the FTSE 100. Therefore, $d p_{t}$ is the difference between log dividends and log prices. Earnings are also considered as the 12-month moving sums of the index's earnings, thus our $e p_{t}$ is the difference of log earnings to log prices. Finally, we construct $d e_{t}$ as the difference of log dividends to log earnings (see the discussion in Campbell and Shiller, 1998; Lamont, 1998; Welch and Goyal, 2007; Ang and Bekaert, 2007).

Our efforts focus on retrieving the predictive ability of $b p_{t}, d p_{t}, e p_{t}$, and $d e_{t}$ on returns, earnings and dividend growth of the entire index. We also examine the trends among individual components of these forecasters, and find two cointegration relationships; one among prices (p), dividends (d) and earnings (e), and another in prices, book values (b) and earnings. We consequently form $p d e_{t}$ and $p b e_{t}$ and examine their performance in our portfolios. Our analysis exploits the size criterion and seeks linkages between the market capitalization value of stocks and the predictability of the selected variables. The entire data set is provided by Bloomberg database.

\subsection{Estimating the co-integration among the series}

In this paper we follow the multivariate Johansen methodology (1995a) which tests for the presence of multiple cointegration relations. The implementation of the technique itself can be divided into several steps, in the first of which we need to test the order of integration of each variable entering the multivariate model. Second, we need to set the suitable lag length of the VAR and third, test and determine the reduced rank of the matrix $\Pi=\alpha \beta^{\prime}$. In the fourth step, we need to decide whether trends exist in the data, and thus, deterministic variables should enter the cointegration space. Finally, we examine the case of weak exogeneity and test for unique cointegration vectors by setting restrictions on $\alpha$ and $\beta$.

More specifically, in our study we are interested in examining the presence and number of cointegration relations in two systems of variables: $w_{t}^{\prime}=\left[p_{t}, d_{t}, e_{t}\right]^{\prime}$ and $z_{t}^{\prime}=\left[p_{t}, b_{t}, e_{t}\right]^{\prime}$ on the index's monthly data based on the assumption that all variables included in both systems are $\mathrm{I}(1)$ as verified by unit root tests. The Johansen approach essentially estimates a Vector Error Correction (VEC) model and concludes its rank by the size of the eigenvalues of an impact matrix $\Pi=\alpha \beta^{\prime}$, where $\alpha$ is the speed of adjustment to disequilibrium while $\beta$ is the matrix of long-run coefficients such that the term $\beta^{\prime} w_{t-1}$ embedded in the VECM of eq. (3.7) below stands for up to (n-1) cointegration relationships in the multivariate model. 
We firstly assume that there are two separate three-dimension vectors $w_{t}^{\prime}=\left[p_{t} d_{t} e_{t}\right]$ and $z_{t}^{\prime}=\left[p_{t} b_{t} e_{t}\right]$ and two cointegration vectors $\mathrm{b}$ and c exist respectively. Then the errors in the data set are represented by $b^{\prime} w_{t-1}$ and $c^{\prime} z_{t-1}$. Our $p d e_{t}$ and $p b e_{t}$ variables refer to the trend deviations from the long-run equilibrium between prices, dividends and earnings on the one hand, and prices, book values and earnings on the other.

$$
\begin{aligned}
& p d e_{t}=p_{t}-\gamma_{1} d_{t}-\gamma_{2} e_{t} \\
& \text { pbe }_{t}=p_{t}-\delta_{1} b_{t}-\delta_{2} e_{t}
\end{aligned}
$$

We proceed by normalizing each vector and setting the coefficient on price equal to one, therefore each cointegration relation is denoted as $g^{\prime}=\left(1,-\gamma_{1},-\gamma_{2}\right)$ for the vector $w_{t}^{\prime}$ and $p^{\prime}=\left(1,-\delta_{1},-\delta_{2}\right)$ for the vector $z_{t}^{\prime}$. In order to estimate the parameters $\gamma_{1}, \gamma_{2}$ and $\delta_{1}, \delta_{2}$ we examine both systems in separate VAR models in levels. Based on the aforementioned steps of the technique, we commence with two unrestricted VAR models involving up to $k$ lags of the form:

$$
w_{t}=A_{1} w_{t-1}+\cdots+A_{k} w_{t-k}+u_{t} \quad U_{t} \sim \operatorname{IN}(0, \Sigma)
$$

where, $w_{t}=\left[\begin{array}{lll}p_{t} & d_{t} & e_{t}\end{array}\right]^{\prime}$ and each $A_{i}$ is an $(3 \times 1)$ matrix of parameters. A similar VAR is formed for $z_{t}=\left[p_{t} b_{t} e_{t}\right]^{\prime}$. We then test for lag length criteria by assuming a high initial number of auto-regressive lags (that is 12 since we are dealing with monthly data). Based on Hannan-Quinn criterion (HQ) ${ }^{2}$, we condition down to a more harmonious representation of using 2 lags for VAR, and thus 1 lag for VECM in both vectors. Eq. (3.6) is the then formulated in a VECM following the form of:

$$
\Delta w_{t}=v+\beta \widehat{g}^{\prime} w_{t-1}+\Gamma(L) \Delta w_{t-1}+e_{t}
$$

where, $\Delta \mathrm{w}_{t}$ is the $(3 \mathrm{x} 1)$ vector of $\log$ first differences for $\left(\Delta p_{t}, \Delta d_{t}, \Delta e_{t}\right)^{\prime}, \mathrm{u}$ and $\beta$ are $(3 \times 1)$ vectors, $\Gamma(L)$ is a finite order distributed lag operator, and $\hat{g}$ is the $(3 \times 1)$ vector of previously estimated cointegration coefficients. A similar set of equation holds for $\left(\Delta p_{t}, \Delta b_{t}, \Delta e_{t}\right)^{\prime}$ where we replace $\hat{g}$ with $\hat{p}$.

We consider the Trace statistic values as our identification criterion of cointegration, under the null hypothesis $\left(H_{0}\right)$ that there are exactly $\mathrm{r}$ cointegrating relations against the alternative $\left(H_{1}\right)$ that there are $\mathrm{p}$ cointegration relations (where $\mathrm{p}$ is the number of the series included in each vector) ${ }^{3}$. Regarding the determination of critical values, we consider that our log series have linear trends but the cointegration relation consists of only a constant (see the discussion in Johansen, 1995 about these assumptions).

Table 1: Cointegration table and the null hypothesis $\left[\begin{array}{lll}1 & -1 & 0\end{array}\right]$ for $\boldsymbol{p} \boldsymbol{d} \boldsymbol{e}_{\boldsymbol{t}}$. The table presents the results of the Johansen test on the pair [p d e], to retrieve evidence of cointegration relationships among prices (p), 12-month summed dividends (d) and 12-month summed earnings (e). Panel B tests the restriction that [ 1 - 10 o $]$ spans the cointegration space among (p, d, e). $5 \%$ and $1 \%$ significance are denoted by $* *$ and $* * *$ respectively. Data is monthly, covering the period 1996:01-2016:12

\begin{tabular}{cccc}
\hline Panel A & Coint. Vector & Trace test stat. & 5\% crit. value \\
\hline & 0 & $38.48^{* *}$ & 29.80 \\
& $\leq 1$ & 9.12 & 15.49 \\
Panel B & $\leq 2$ & 0.64 & 3.84 \\
& $\mathbf{H}_{\mathbf{o}}:\left[\begin{array}{lll}\mathbf{1}-\mathbf{1} & \mathbf{0}\end{array}\right]$ & $\boldsymbol{\chi}^{\mathbf{2}}$-stat. & \\
\hline
\end{tabular}

Source: Bloomberg database

Table 2: Cointegration table and the null hypothesis $\left[\begin{array}{lll}1 & -1 & 0\end{array}\right]$ for $\boldsymbol{p} \boldsymbol{b} \boldsymbol{e}_{\boldsymbol{t}}$. The table presents the results of the Johansen test on the pair [ p b e], to retrieve evidence of cointegration relationships among prices (p), book values (b) and 12month summed earnings (e). Panel B tests the restriction that [ $\left.\begin{array}{lll}1 & -1 & 0\end{array}\right]$ spans the cointegration space among (p, b, e). $5 \%$ and $1 \%$ significance are denoted by $* *$ and $* * *$ respectively. Data is monthly, covering the period 1996:01-2016:12

\begin{tabular}{cccc}
\hline Panel A & Coint. Vector & Trace test stat. & 5\% crit. value \\
\hline & 0 & $40.87^{* *}$ & 29.80 \\
& $\leq 1$ & 11.77 & 15.49 \\
Panel B & $\leq 2$ & 3.73 & 3.84 \\
& $\mathbf{H}_{\mathbf{o}}:\left[\begin{array}{ll}\mathbf{1}-\mathbf{1} & \mathbf{0}\end{array}\right]$ & $\boldsymbol{\chi}^{2}$-stat. & \\
\hline
\end{tabular}

Source: Bloomberg database

The evidence in Tables 1 and 2 strongly suggest that there is a single cointegration relationship in each system following the forms:

$$
p d e_{t}=p_{t}+0.0485 d_{t}-2.7270 e_{t}
$$

\footnotetext{
${ }^{2}$ See the discussion in Johansen et al. (2000) for the reason why this specific criterion is utilized against the alternatives, even though results are similar if one prefers to use the Akaike Information Criterion (AIC).

${ }^{3}$ We have also considered L-max statistic to identify cointegration with no significant changes in the outcomes.
} 


$$
p b e_{t}=p_{t}-0.6161 b_{t}-0.3967 e_{t}
$$

Also, Panel B of both Tables examines the restriction that $\left[\begin{array}{lll}1 & -1 & 0\end{array}\right]$ spans the cointegration space of the Johansen methodology on $\left[p_{t} d_{t} e_{t}\right]$ and $\left[p_{t} b_{t} e_{t}\right]$ and confirms that it does not. This consists an even stronger indication that our series are indeed I(1) processes.

\section{Results}

This section presents the empirical findings and proceeds on interpreting the outcomes.

\subsection{Descriptive statistics}

Table 3 reports the descriptive statistics of the FTSE 100 after the construction of the size portfolios of returns (Panel A), of the dividends growth rate (Panel B), earnings growth rate (Panel C) and the selected predictive variables (Panel D) for the period 1996:01-2016:12. Certain patterns that are related to the rest of this paper are boldfaced and discussed below.

Table 3: Data summary of the FTSE 100 returns $\left(r_{t}\right)$, dividend growth $\left(\boldsymbol{\Delta} \boldsymbol{d}_{\boldsymbol{t}}\right)$ and earnings growth $\left(\boldsymbol{\Delta} \boldsymbol{e}_{\boldsymbol{t}}\right)$, covering the period 1996:01-2016:12 as provided by Bloomberg database. The mean, standard deviation and autocorrelation coefficient based on an $\mathrm{AR}(1)$ model of returns, dividends and earnings growth are reported. Panel A consists of the returns of the size portfolios based on the market capitalization criterion, while Panels B and C report the portfolios' dividend and earnings growth rates respectively. Panel D includes the selected financial ratios employed. The discussed numbers in the text are boldfaced.

\begin{tabular}{lccc}
\hline Size portfolios & Mean & Std & AR(1) \\
\hline Panel A: Returns & & & \\
\hline Small & $\mathbf{2 . 1 6}$ & $\mathbf{0 . 5 4}$ & 0.89 \\
Medium & $\mathbf{2 . 2 0}$ & $\mathbf{0 . 5 3}$ & 0.94 \\
Large & $\mathbf{2 . 2 5}$ & $\mathbf{0 . 3 9}$ & 0.84 \\
\hline Panel B: Dividend growth & & & \\
\hline Small & 0.74 & $\mathbf{0 . 3 9}$ & 0.01 \\
Medium & 0.74 & $\mathbf{0 . 1 6}$ & -0.11 \\
Large & $\mathbf{0 . 9 5}$ & $\mathbf{0 . 3 9}$ & 0.08 \\
\hline Panel C: Earnings growth & & & \\
\hline Small & $\mathbf{0 . 8 9}$ & $\mathbf{0 . 4 2}$ & 0.95 \\
Medium & 0.71 & 0.06 & -0.05 \\
Large & 0.71 & 0.12 & -0.03 \\
\hline Panel D: Predictive variables & & & \\
\hline$b p_{t}$ & -0.87 & $\mathbf{0 . 4 8}$ & 0.95 \\
$d p_{t}$ & 3.69 & 0.22 & $\mathbf{1 . 0 1}$ \\
$e p_{t}$ & -0.59 & $\mathbf{0 . 4 5}$ & 0.98 \\
$d e_{t}$ & 4.29 & 0.38 & 0.99 \\
pde & 8.62 & $\mathbf{0 . 6 1}$ & $\mathbf{1 . 0 0}$ \\
pbe & 8.22 & 0.24 & 0.94 \\
\hline
\end{tabular}

Three points are highlighted. First, the mean values of the returns portfolios are much higher compared to both earnings and dividend growth portfolios. Specifically, we receive greater mean values of 2.16 to 2.25 in the return portfolios, while in Panels $\mathrm{B}$ and $\mathrm{C}$ the highest mean value is noticed in the large portfolio of dividend growth at 0.95 and in the small portfolio of earnings growth at 0.89 .

Second, Table 3 shows that small and medium portfolios' returns are considerably more volatile at 0.54 and 0.53 respectively, compared to 0.39 for the large portfolio. However, in Panel B an interesting indication is that both the small and the large portfolio are equally volatile at 0.39 , while the medium one provides almost half the respective value of standard deviation. In the case of earnings growth portfolios, the highest volatility is observed in the small portfolio at 0.42 .

Third, our constructed variable $p d e_{t}$ depicts the highest volatility at 0.61 , with $b p_{t}$ and $e p_{t}$ follow at 0.48 and 0.45 equivalently. All of our predictors seem to be highly persistent, particularly $d p_{t}$ with an $\operatorname{AR}(1)$ value of 1.01 and $p d e_{t}$ at 1.00. The fact that persistent variables are well claimed to provide increased values of slope coefficients in longer horizons is clearly discussed and identified several times in the finance literature, starting early on from Miller and Modigliani (1961), Fama and French (1988) and later by Cochrane (1991), Lettau and Ludvigson (2001) and many others.

To illustrate extra patterns that are evident among returns, dividend and earnings growth and our newly constructed variables, $p d e_{t}$ and $p b e_{t}$, we plot all series on separate graphs. Figure 1 shows that there are several time periods that returns move to the exact opposite direction with $p b e_{t}$, namely 1998-2001 and 2002-2010. Also, large negative spikes of $p d e_{t}$, in the periods 2008-2009 and 2011-2013 co-exist with sudden increases in returns, indicating that huge decreases in either prices or earnings were accompanied by even greater increases in dividends which kept 
returns positive during a time period of severe economic turbulences worldwide. Dividend growth on the other hand, provides several positive spikes that co-exist with either much lower values of $p d e_{t}$ or $p b e_{t}$, except the period 20122015 that all series follow a positive uprising trend. Finally, the plot on earnings growth reveals that after 2013 sudden increases are clearly more evident that overcome in magnitude the respective fluctuations of both $p d e_{t}$ and $p b e_{t}$. From the beginning of our sample till 2013 though, minor fluctuations in earnings growth do not exhibit any interpretable behavior in conjunction with sudden drops and increases derived by either $p d e_{t}$ or $p b e_{t}$. Overall, if the center of our focus is the recent financial crisis' period (2008-2010), the index's returns do depict significant fluctuations since prices drop significantly while both dividend and earnings growth are not as severely affected.
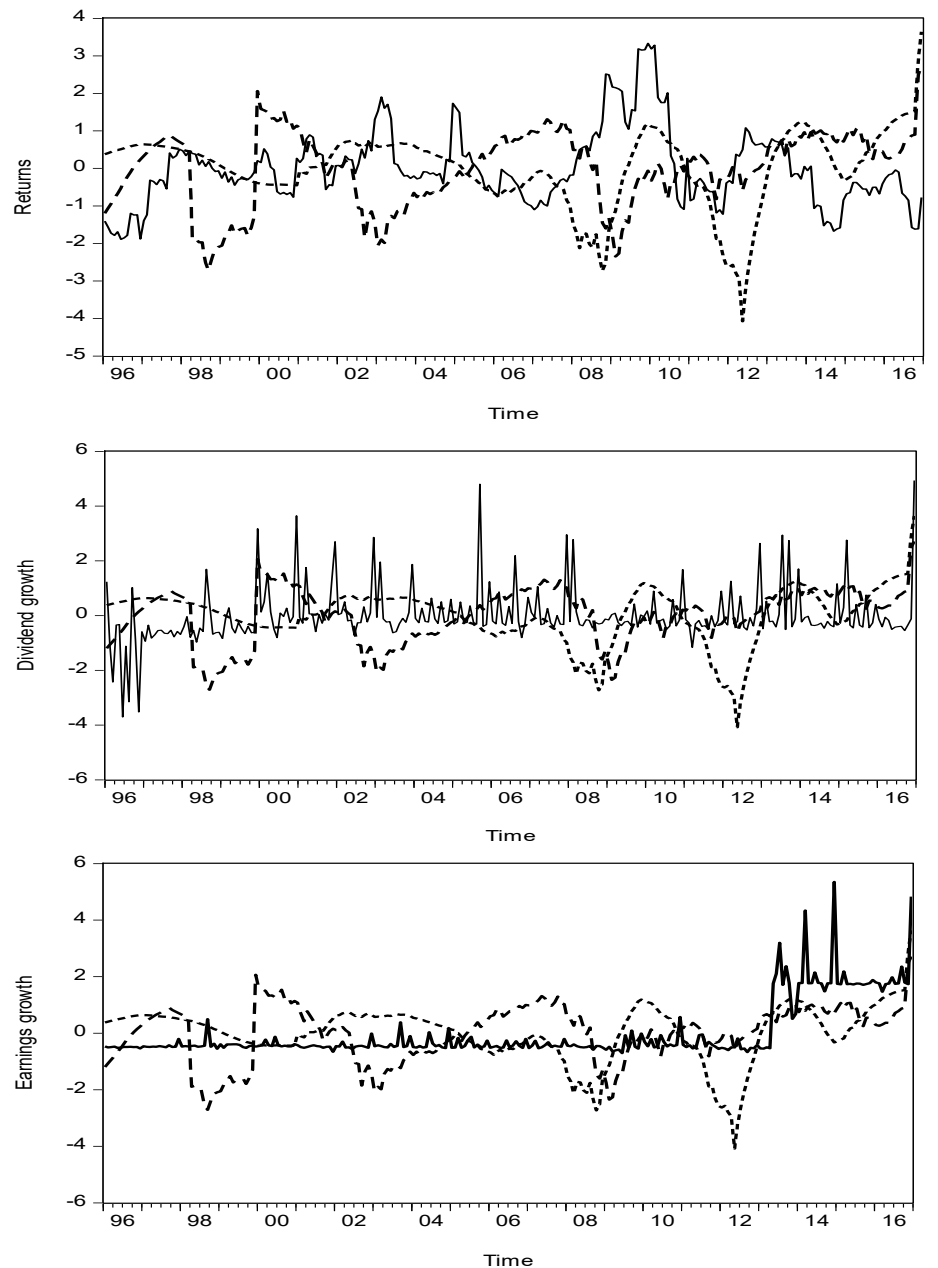

Figure 1: Returns, dividend growth and earnings growth, covering the period 1996:01-2016:12 as provided by Bloomberg database. The figure compares returns, dividend and earnings growth (solid line in each graph) to $\boldsymbol{p d} \boldsymbol{e}_{\boldsymbol{t}}$ (dashed line) and $\boldsymbol{p} \boldsymbol{b} \boldsymbol{e}_{\boldsymbol{t}}$ (double dashed line)

Finally, in Figure 2 we isolate our two constructed variables $p d e_{t}$ and $p b e_{t}$ and examine their behavior in the sample. We notice that these trend relations tend to move together after 2005, except the late 2012 when there is a huge negative spike in $p b e_{t}$ although they both show a declining pattern. Overall, declining values in $p b e_{t}$ seem to lead to increasing upcoming values of $p d e_{t}$ and vice versa. 


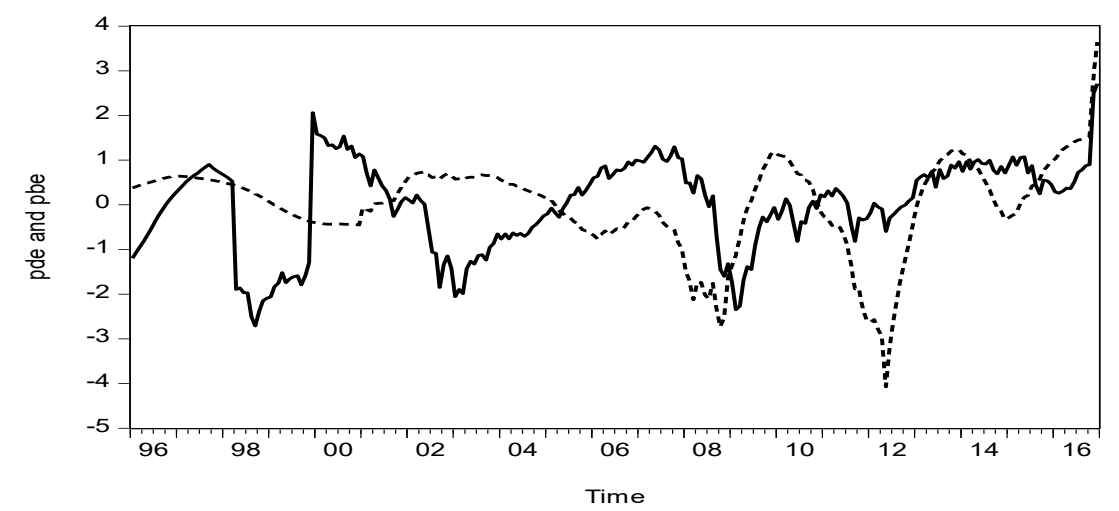

Figure 2: Long-run equilibrium relationships among $\left[\boldsymbol{p}_{\boldsymbol{t}}, \boldsymbol{d}_{\boldsymbol{t}}, \boldsymbol{e}_{\boldsymbol{t}}\right]$ (solid line) and $\left[\boldsymbol{p}_{\boldsymbol{t}}, \boldsymbol{b}_{\boldsymbol{t}}, \boldsymbol{e}_{\boldsymbol{t}}\right]$ (dashed line), covering the period 1996:01-2016:12 as estimated by authors' calculations.

\subsection{Monthly long-horizon regressions}

In this sub-section, we report the results of the forecasting regressions of the returns and the growth rates of dividend and earnings for the three size portfolios on the FTSE 100 stock market index at horizons ranging from 1 to $24-$ months. Our regressions follow the spirit of Cochrane (2009) on our selected financial ratios, namely $b p_{t}, d p_{t}, e p_{t}$, $d e_{t}$ and our constructed variables from the cointegration relationships (see section 3.2 in this paper), $p d e_{t}$ and $p b e_{t}$. We firstly construct continuously compounded returns, dividend and earnings growth for all horizons and then we consider the following regression on monthly data:

$$
y_{t+h}=\alpha_{h}+\beta_{h} \chi_{t}+\varepsilon_{t+h}
$$

where $y_{t+h}$ is either return, dividend or earnings growth at month $t$, and $\chi_{t}$ is either $b p_{t}, d p_{t}, e p_{t}, d e_{t}, p d e_{t}$ or $p b e_{t}$. Tables 4, 5 and 6 report the regression coefficient in the first row, the t-statistics in parenthesis in the second row (following a GMM correction for heteroscedasticity and serial correlation) and $R^{2}$ in the third row. Consequently, our discussion focuses on three dimensions, the slope size (regressions' coefficients values), significance (t-statistics) and explanatory power $\left(R^{2}\right)^{4}$

Table 4: In-sample predictability of continuously compounded returns $\left(r_{t}\right)$ of the size portfolios on the selected financial ratios and the long-run equilibrium relationship of $\left[\boldsymbol{p}_{\boldsymbol{t}}, \boldsymbol{d}_{\boldsymbol{t}}, \boldsymbol{e}_{\boldsymbol{t}}\right]$ and $\left[\boldsymbol{p}_{\boldsymbol{t}}, \boldsymbol{b}_{\boldsymbol{t}}, \boldsymbol{e}_{\boldsymbol{t}}\right]$, covering the period 1996:012016:12. The first row reports the regression coefficient, t-statistics is reported in parenthesis in the second row and the third row reports $\boldsymbol{R}^{2}$. Standard errors are GMM corrected. Boldfaced numbers are discussed in the text

\begin{tabular}{|c|c|c|c|c|c|}
\hline$h$ & 1 & 6 & 12 & 18 & 24 \\
\hline \multicolumn{6}{|c|}{ Panel A: Small } \\
\hline \multirow[t]{3}{*}{$b p_{t}$} & 0.19 & 7.66 & 6.81 & 21.57 & 31.52 \\
\hline & $(2.45)$ & $(2.39)$ & $(3.26)$ & $(3.56)$ & (3.93) \\
\hline & 0.02 & 0.01 & 0.05 & 0.09 & 0.07 \\
\hline \multirow[t]{3}{*}{$d p_{t}$} & 0.33 & 8.42 & 7.93 & 27.69 & 44.70 \\
\hline & $(3.81)$ & $(2.20)$ & $(1.62)$ & $(1.57)$ & $(1.59)$ \\
\hline & 0.03 & 0.02 & 0.06 & 0.14 & 0.10 \\
\hline \multirow[t]{3}{*}{$e p_{t}$} & -0.09 & -2.08 & 2.93 & 16.84 & 36.93 \\
\hline & $(-1.47)$ & $(-1.15)$ & $(2.42)$ & $(3.65)$ & $(4.45)$ \\
\hline & 0.01 & 0.00 & 0.02 & 0.13 & 0.17 \\
\hline \multirow[t]{3}{*}{$d e_{t}$} & -0.08 & 4.67 & 7.15 & -8.71 & -29.04 \\
\hline & $(-0.77)$ & $(1.62)$ & $(0.08)$ & $(-2.99)$ & $(-3.86)$ \\
\hline & 0.00 & 0.01 & 0.00 & 0.02 & 0.06 \\
\hline \multirow[t]{3}{*}{$\operatorname{pde}_{t}$} & -0.07 & 2.33 & -6.86 & -10.21 & -31.86 \\
\hline & $(-1.36)$ & $(1.30)$ & $(-0.09)$ & $(-2.86)$ & $(-3.71)$ \\
\hline & 0.01 & 0.00 & 0.00 & 0.08 & 0.20 \\
\hline \multirow[t]{3}{*}{$\mathrm{pbe}_{\mathrm{t}}$} & -0.28 & -1.22 & -9.78 & -28.68 & -22.27 \\
\hline & $(-3.00)$ & $(-3.84)$ & $(-3.58)$ & $(-3.31)$ & $(-2.16)$ \\
\hline & 0.02 & 0.02 & 0.06 & 0.11 & 0.02 \\
\hline \multicolumn{6}{|c|}{ Panel B: Medium } \\
\hline \multirow[t]{3}{*}{$b p_{t}$} & 0.28 & 2.15 & 13.82 & 5.97 & 10.95 \\
\hline & $(2.66)$ & $(5.40)$ & $(4.81)$ & $(3.47)$ & $(3.25)$ \\
\hline & 0.04 & 0.10 & 0.11 & 0.05 & 0.01 \\
\hline$d p_{t}$ & 0.22 & 1.65 & 1.45 & 7.64 & 16.35 \\
\hline
\end{tabular}

\footnotetext{
${ }^{4}$ Due to their size and in order to avoid confusion, our analysis in this sub-section is mainly focused on the most significant insample outcomes of Tables 4, 5 and 6.
} 


\begin{tabular}{|c|c|c|c|c|c|}
\hline & $(1.41)$ & $(1.60)$ & $(1.61)$ & $(1.54)$ & $(1.56)$ \\
\hline & 0.01 & 0.05 & 0.10 & 0.08 & 0.03 \\
\hline \multirow{3}{*}{$e p_{t}$} & -0.11 & 3.08 & 9.11 & 6.57 & 20.47 \\
\hline & $(-1.09)$ & (0.69) & $(3.27)$ & $(3.66)$ & $(3.56)$ \\
\hline & 0.01 & 0.00 & 0.10 & 0.14 & 0.27 \\
\hline \multirow[t]{3}{*}{$d e_{t}$} & 0.35 & 7.62 & -3.92 & -4.90 & -20.55 \\
\hline & $(3.55)$ & $(1.88)$ & $(-1.74)$ & $(-3.29)$ & $(-3.42)$ \\
\hline & 0.06 & 0.02 & 0.01 & 0.05 & 0.07 \\
\hline \multirow{3}{*}{$\mathrm{pde}_{\mathrm{t}}$} & -0.09 & -6.46 & -8.03 & -6.35 & -20.03 \\
\hline & $(-1.29)$ & $(-1.81)$ & $(-3.26)$ & $(-3.45)$ & $(-3.28)$ \\
\hline & 0.01 & 0.03 & 0.12 & 0.22 & 0.35 \\
\hline \multirow[t]{3}{*}{$\mathrm{pbe}_{\mathrm{t}}$} & -1.02 & -2.98 & -14.02 & -31.10 & 13.96 \\
\hline & $(-7.71)$ & $(-5.43)$ & $(-3.43)$ & $(-1.50)$ & $(2.63)$ \\
\hline & 0.21 & 0.12 & 0.07 & 0.02 & 0.01 \\
\hline \multicolumn{6}{|c|}{ Panel C: Large } \\
\hline \multirow[t]{3}{*}{$b p_{t}$} & 0.17 & 9.78 & 4.36 & 14.89 & 37.71 \\
\hline & $(1.98)$ & $(5.15)$ & $(5.43)$ & $(4.62)$ & $(4.06)$ \\
\hline & 0.03 & 0.09 & 0.10 & 0.10 & 0.08 \\
\hline \multirow[t]{3}{*}{$d p_{t}$} & 0.28 & 8.12 & 25.84 & 7.32 & 14.12 \\
\hline & $(1.61)$ & $(1.75)$ & $(1.77)$ & $(1.72)$ & $(1.70)$ \\
\hline & 0.04 & 0.05 & 0.03 & 0.02 & 0.01 \\
\hline \multirow[t]{3}{*}{$e p_{t}$} & 0.22 & 7.62 & 3.57 & 12.33 & 29.34 \\
\hline & $(4.69)$ & $(5.61)$ & $(5.24)$ & $(5.78)$ & (6.05) \\
\hline & 0.06 & 0.11 & 0.15 & 0.16 & 0.20 \\
\hline \multirow[t]{3}{*}{$d e_{t}$} & -0.09 & -5.12 & -3.89 & -13.29 & -34.61 \\
\hline & $(-1.49)$ & $(-3.37)$ & $(-4.72)$ & $(-4.42)$ & $(-3.77)$ \\
\hline & 0.01 & 0.03 & 0.08 & 0.11 & 0.09 \\
\hline \multirow[t]{3}{*}{$\mathrm{pde}_{\mathrm{t}}$} & -0.06 & -4.13 & -3.25 & -15.93 & -40.56 \\
\hline & $(-1.22)$ & $(-2.94)$ & $(-5.10)$ & $(-5.57)$ & $(-4.47)$ \\
\hline & 0.01 & 0.05 & 0.20 & 0.40 & 0.47 \\
\hline \multirow[t]{2}{*}{$\mathrm{pbe}_{\mathrm{t}}$} & 0.09 & 3.44 & 1.40 & 12.38 & 21.42 \\
\hline & (0.98) & $(1.70)$ & $(2.19)$ & $(0.86)$ & $(0.58)$ \\
\hline
\end{tabular}

Table 4 shows that evidence of return predictability is primarily focused on the medium and large-size portfolios; in fact, $e p_{t}$, and $p d e_{t}$ manage to explain $27 \%$ and $35 \%$ of returns variations in the medium portfolio at $h=24$. The forecasting power of $p d e_{t}$ is even more impressive in the large portfolio, reaching a $R^{2}$ of $47 \%$ at our longest horizon, and providing significant but negative coefficients in all horizons. Also, another forecaster with large and positive values of coefficients and rising $R^{2} s$ till $20 \%$ at $h=24$ is $e p_{t}$. However, our second constructed variable based on the long-run equilibrium of $\left[p_{t}, d_{t}, e_{t}\right]$ is rather weak in explaining return variations regardless of size. Overall, $p d e_{t}$ and $e p_{t}{ }^{\prime} s$ forecasting power is mostly distinguishable in the returns portfolios and is mainly evident in the medium and large-size securities. Also, unlike the strong forecasting ability of $d p_{t}$ in US data sets reported in similar studies (see for example, Campbell and Shiller, 2001; Campbell and Yogo, 2006), here in the British data, and in particular when sorted in portfolios, it seems unable to provide any significant results.

Table 5: In-sample predictability of continuously compounded dividend growth $\left(\boldsymbol{\Delta} \boldsymbol{d}_{\boldsymbol{t}}\right)$ of the size portfolios on the selected financial ratios and the long-run equilibrium relationships of $\left[\boldsymbol{p}_{\boldsymbol{t}}, \boldsymbol{d}_{\boldsymbol{t}}, \boldsymbol{e}_{\boldsymbol{t}}\right]$ and $\left[\boldsymbol{p}_{\boldsymbol{t}}, \boldsymbol{b}_{\boldsymbol{t}}, \boldsymbol{e}_{\boldsymbol{t}}\right]$, covering the period 1996:01-2016:12. The first row reports the regression coefficient, $t$-statistics is reported in parenthesis in the second row and the third row reports $\boldsymbol{R}^{\mathbf{2}}$. Standard errors are GMM corrected. Boldfaced numbers are discussed in the text

\begin{tabular}{lccccc}
\hline$h$ & 1 & 6 & 12 & 18 & 24 \\
\hline Panel A: Small & & & & & -67.45 \\
\hline$b p_{t}$ & -0.11 & -4.76 & -3.66 & -15.36 & $(-4.63)$ \\
& $(-1.09)$ & $(-1.12)$ & $(-3.01)$ & $(-4.01)$ & 0.13 \\
$d p_{t}$ & 0.01 & 0.01 & 0.07 & 0.10 & -39.86 \\
& 0.17 & 6.02 & 14.94 & 42.92 & $(-0.24)$ \\
& $(1.99)$ & $(3.18)$ & $(2.22)$ & $(2.06)$ & 0.00 \\
$e p_{t}$ & 0.02 & 0.02 & 0.01 & 0.01 & 89.33 \\
& 0.03 & 0.65 & 85.01 & 47.56 & $(1.59)$ \\
$d e_{t}$ & $(0.56)$ & $(0.39)$ & $(2.05)$ & $(3.42)$ & 0.00 \\
& 0.00 & 0.00 & 0.01 & 0.02 & -26.67 \\
& -0.08 & -5.84 & -25.39 & -92.71 & $(-3.39)$ \\
\hline
\end{tabular}




\begin{tabular}{|c|c|c|c|c|c|}
\hline \multirow[t]{3}{*}{$\mathrm{pde}_{\mathrm{t}}$} & -0.02 & -2.31 & -85.65 & -35.89 & -88.50 \\
\hline & $(-0.53)$ & $(-2.26)$ & $(-2.53)$ & $(-2.60)$ & $(-1.79)$ \\
\hline & 0.00 & 0.01 & 0.01 & 0.02 & 0.01 \\
\hline \multirow{3}{*}{$\mathrm{pbe}_{\mathrm{t}}$} & 0.05 & -6.69 & -32.78 & -14.16 & -26.76 \\
\hline & $(0.41)$ & $(-1.60)$ & $(-2.48)$ & $(-2.89)$ & $(-1.48)$ \\
\hline & 0.00 & 0.01 & 0.03 & 0.05 & 0.01 \\
\hline \multicolumn{6}{|c|}{ Panel B: Medium } \\
\hline \multirow[t]{3}{*}{$b p_{t}$} & -0.01 & 4.70 & 27.08 & 12.06 & 45.24 \\
\hline & $(-0.17)$ & $(5.75)$ & $(6.17)$ & $(6.75)$ & $(7.73)$ \\
\hline & 0.00 & 0.07 & 0.12 & 0.18 & 0.23 \\
\hline \multirow[t]{3}{*}{$d p_{t}$} & 0.06 & 3.70 & 18.83 & 73.95 & 23.55 \\
\hline & $(1.43)$ & $(1.90)$ & $(1.94)$ & $(1.99)$ & $(2.12)$ \\
\hline & 0.01 & 0.04 & 0.05 & 0.06 & 0.06 \\
\hline \multirow[t]{3}{*}{$e p_{t}$} & 0.03 & 2.66 & 16.51 & 77.06 & 27.79 \\
\hline & $(1.86)$ & $(4.07)$ & $(4.28)$ & $(5.05)$ & $(5.82)$ \\
\hline & 0.01 & 0.05 & 0.09 & 0.16 & 0.19 \\
\hline \multirow[t]{3}{*}{$d e_{t}$} & -0.01 & -2.19 & -16.13 & -79.95 & -30.97 \\
\hline & $(-0.69)$ & $(-3.75)$ & $(-4.33)$ & $(-4.94)$ & $(-5.72)$ \\
\hline & 0.00 & 0.02 & 0.06 & 0.11 & 0.15 \\
\hline \multirow[t]{3}{*}{$\operatorname{pde}_{\mathrm{t}}$} & 0.01 & -0.05 & -86.24 & -69.27 & -25.76 \\
\hline & $(0.46)$ & $(-0.10)$ & $(-2.61)$ & $(-4.52)$ & $(-5.66)$ \\
\hline & 0.00 & 0.00 & 0.04 & 0.20 & 0.26 \\
\hline \multirow[t]{3}{*}{$\mathrm{pbe}_{\mathrm{t}}$} & 0.06 & 4.71 & 20.90 & 53.95 & 16.13 \\
\hline & $(1.97)$ & $(4.19)$ & $(5.90)$ & $(4.61)$ & $(3.70)$ \\
\hline & 0.01 & 0.04 & 0.04 & $0.05^{\prime}$ & 0.06 \\
\hline \multicolumn{6}{|c|}{ Panel C: Large } \\
\hline \multirow[t]{3}{*}{$b p_{t}$} & -0.01 & 27.26 & 13.89 & 41.16 & -11.62 \\
\hline & $(-0.05)$ & $(5.27)$ & $(2.41)$ & $(0.92)$ & $(-0.31)$ \\
\hline & 0.00 & 0.07 & 0.03 & 0.00 & 0.00 \\
\hline \multirow[t]{3}{*}{$d p_{t}$} & 0.13 & 5.27 & 13.26 & 15.95 & -25.74 \\
\hline & $(1.46)$ & $(1.15)$ & $(0.25)$ & $(0.45)$ & $(-0.01)$ \\
\hline & 0.01 & 0.00 & 0.00 & 0.00 & 0.00 \\
\hline \multirow[t]{3}{*}{$e p_{t}$} & 0.03 & -2.60 & -93.78 & -10.40 & -9.85 \\
\hline & (0.59) & $(-0.70)$ & $(-3.06)$ & $(-3.91)$ & $(-4.41)$ \\
\hline & 0.00 & 0.00 & 0.03 & 0.06 & 0.04 \\
\hline \multirow[t]{3}{*}{$d e_{t}$} & -0.09 & -17.86 & -15.19 & -11.23 & -7.26 \\
\hline & $(-1.25)$ & $(-3.58)$ & $(-4.31)$ & $(-3.61)$ & $(-3.52)$ \\
\hline & 0.01 & 0.04 & 0.05 & 0.04 & 0.04 \\
\hline \multirow[t]{3}{*}{$\mathrm{pde}_{\mathrm{t}}$} & -0.01 & -4.89 & -29.20 & -35.80 & -23.36 \\
\hline & $(-0.22)$ & $(-1.99)$ & $(-1.61)$ & $(-2.07)$ & $(-2.07)$ \\
\hline & 0.00 & 0.01 & 0.01 & 0.01 & 0.04 \\
\hline \multirow[t]{3}{*}{$\mathrm{pbe}_{\mathrm{t}}$} & 0.42 & 48.00 & 47.25 & 29.33 & 22.06 \\
\hline & $(4.34)$ & $(6.49)$ & $(8.75)$ & $(5.10)$ & $(4.89)$ \\
\hline & 0.07 & 0.13 & 0.23 & 0.25 & 0.29 \\
\hline
\end{tabular}

Turning to long-horizon forecasts of dividend growth in Table 5, again most predictive components of our selected ratios are found in our medium portfolio. More specifically, the t-statistics from the forecasting regressions on $b p_{t}$ and $e p_{t}$ are all above four from 6 to 24-month horizon; simultaneously, $R^{2}$ keeps augmenting, reaching the highest values at $h=24$ of $23 \%$ from $b p_{t}$ and $19 \%$ from $e p_{t}$.

Furthermore, $p d e_{t}$ proves rather explicable, the more we extend the horizon, with an $R^{2}$ value of $26 \%$ at $h=24$, and rising values of regressions coefficients in absolute values. Further predictive evidence is noticed by $d p_{t}$, $d e_{t}$, and $p b e_{t}$ with a more impressive performance derived by $d e_{t}$ with large significant t-statistics and $R^{2}$ of $15 \%$ at its highest. Focusing on the discussion of the coefficients' sign, we also observe that $d p_{t}$ forecasts dividend growth but with the wrong sign; when prices are higher compared to dividends, higher dividend growth should be forecasted (see the discussion in Cochrane, 1991; Campbell, 2003; Lettau and Ludvigson, 2005). Such empirical evidence is no news in the forecasting literature, but the fact that the same applies even when the size criterion is taken into consideration is new. Finally, the results of $p d e_{t}$ and $p b e_{t}$ suggest that the latter is a stronger forecaster in the large portfolio, explaining $29 \%$ of the dividend growth variation. The fact that all classical ratios apart from our tri-variate predictors, provide some degree of explicability for the variations in the British dividend growth is impressive enough since they do not manage to perform seemingly in US data (see for example, Cochrane, 2009; Chen, 2009). 
Table 6: In-sample predictability of continuously compounded earnings growth $\left(\boldsymbol{\Delta} \boldsymbol{e}_{\boldsymbol{t}}\right)$ of the size portfolios on the selected financial ratios and the long-run equilibrium relationships of $\left[\boldsymbol{p}_{\boldsymbol{t}}, \boldsymbol{d}_{\boldsymbol{t}}, \boldsymbol{e}_{\boldsymbol{t}}\right]$ and $\left[\boldsymbol{p}_{\boldsymbol{t}}, \boldsymbol{b}_{\boldsymbol{t}}, \boldsymbol{e}_{\boldsymbol{t}}\right]$, covering the period 1996:01-2016:12. The first row reports the regression coefficient, $t$-statistics is reported in parenthesis in the second row and the third row reports $\boldsymbol{R}^{2}$. Standard errors are GMM corrected. Boldfaced numbers are discussed in the text

\begin{tabular}{|c|c|c|c|c|c|}
\hline$h$ & 1 & 6 & 12 & 18 & 24 \\
\hline \multicolumn{6}{|c|}{ Panel A: Small } \\
\hline \multirow[t]{3}{*}{$b p_{t}$} & 0.08 & 14.84 & 60.38 & 22.39 & 8.30 \\
\hline & $(0.48)$ & $(6.53)$ & $(6.04)$ & $(5.50)$ & $(4.90)$ \\
\hline & 0.01 & 0.08 & 0.07 & 0.07 & 0.05 \\
\hline \multirow[t]{3}{*}{$d p_{t}$} & 0.19 & 62.78 & 25.45 & 10.87 & 7.12 \\
\hline & $(1.69)$ & $(1.74)$ & $(1.64)$ & $(1.56)$ & $(1.64)$ \\
\hline & 0.02 & 0.01 & 0.01 & 0.01 & 0.01 \\
\hline \multirow[t]{3}{*}{$e p_{t}$} & 0.03 & 32.94 & 21.39 & 9.46 & 3.84 \\
\hline & $(0.77)$ & $(2.51)$ & $(3.97)$ & $(3.52)$ & $(2.87)$ \\
\hline & 0.00 & 0.01 & 0.02 & 0.02 & 0.02 \\
\hline \multirow[t]{3}{*}{$d e_{t}$} & 0.11 & 4.25 & -10.48 & -5.32 & -5.92 \\
\hline & $(1.62)$ & $(0.20)$ & $(-1.40)$ & $(-1.72)$ & $(-0.51)$ \\
\hline & 0.01 & 0.00 & 0.00 & 0.00 & 0.00 \\
\hline \multirow[t]{3}{*}{$\mathrm{pde}_{\mathrm{t}}$} & 0.29 & 97.08 & 37.37 & 13.84 & 5.88 \\
\hline & $(6.62)$ & $(6.85)$ & $(7.13)$ & $(4.50)$ & $(4.28)$ \\
\hline & $0.17^{\prime}$ & 0.20 & 0.21 & 0.08 & 0.08 \\
\hline \multirow[t]{3}{*}{$\mathrm{pbe}_{\mathrm{t}}$} & 0.70 & 25.43 & 11.19 & 4.93 & 1.63 \\
\hline & $(6.48)$ & $(6.57)$ & $(6.88)$ & $(5.76)$ & $(4.98)$ \\
\hline & 0.15 & 0.17 & 0.17 & 0.14 & 0.11 \\
\hline \multicolumn{6}{|c|}{ Panel B: Medium } \\
\hline \multirow[t]{3}{*}{$b p_{t}$} & 0.01 & 1.67 & 99.58 & 40.71 & 14.29 \\
\hline & $(1.01)$ & $(4.89)$ & $(8.11)$ & $(11.10)$ & $(15.90)$ \\
\hline & 0.00 & 0.06 & 0.18 & 0.29 & 0.45 \\
\hline \multirow[t]{3}{*}{$d p_{t}$} & 0.01 & 0.44 & 26.35 & 97.54 & 33.21 \\
\hline & $(0.90)$ & $(1.21)$ & $(1.91)$ & $(2.22)$ & $(2.63)$ \\
\hline & 0.00 & 0.00 & 0.01 & 0.01 & 0.02 \\
\hline \multirow{3}{*}{$e p_{t}$} & -0.00 & -0.53 & -25.15 & -59.83 & 48.04 \\
\hline & $(-0.44)$ & $(-1.72)$ & $(-2.04)$ & $(-1.48)$ & $(3.56)$ \\
\hline & 0.00 & 0.01 & 0.02 & 0.03 & 0.07 \\
\hline \multirow[t]{3}{*}{$d e_{t}$} & 0.01 & 1.16 & 65.39 & 20.25 & -50.20 \\
\hline & $(1.12)$ & $(3.40)$ & $(4.89)$ & $(4.44)$ & $(-0.43)$ \\
\hline & 0.00 & 0.04 & 0.10 & 0.10 & 0.00 \\
\hline \multirow[t]{3}{*}{$\mathrm{pde}_{\mathrm{t}}$} & 0.01 & 0.83 & 30.38 & 34.56 & -16.10 \\
\hline & $(1.01)$ & $(3.93)$ & $(3.21)$ & $(0.83)$ & $(-0.16)$ \\
\hline & 0.00 & 0.06 & 0.06 & 0.01 & 0.00 \\
\hline \multirow[t]{3}{*}{$\mathrm{pbe}_{\mathrm{t}}$} & 0.01 & 0.16 & -40.35 & -20.23 & -77.50 \\
\hline & $(0.53)$ & $(0.31)$ & $(-2.33)$ & $(-3.69)$ & $(-4.56)$ \\
\hline & 0.00 & 0.00 & 0.02 & 0.04 & 0.08 \\
\hline \multicolumn{6}{|c|}{ Panel C: Large } \\
\hline \multirow[t]{3}{*}{$b p_{t}$} & -0.09 & 1.27 & 58.73 & 23.82 & 84.56 \\
\hline & $(-1.49)$ & $(2.40)$ & $(3.45)$ & $(4.80)$ & $(6.21)$ \\
\hline & 0.09 & 0.01 & 0.02 & 0.06 & 0.11 \\
\hline \multirow[t]{3}{*}{$d p_{t}$} & 0.03 & -0.23 & 38.06 & 19.49 & 63.16 \\
\hline & (0.68) & $(-0.49)$ & $(1.70)$ & $(1.79)$ & $(1.85)$ \\
\hline & 0.01 & 0.00 & 0.01 & 0.03 & 0.05 \\
\hline$e p_{t}$ & 0.01 & -0.11 & -5.76 & -23.78 & 68.87 \\
\hline & $(0.78)$ & $(-0.35)$ & $(-0.61)$ & $(-0.85)$ & $(0.78)$ \\
\hline & 0.00 & 0.00 & 0.00 & 0.00 & 0.00 \\
\hline$d e_{t}$ & 0.01 & -0.18 & 27.56 & 16.04 & 34.09 \\
\hline & $(0.32)$ & $(-0.37)$ & $(2.19)$ & $(4.08)$ & $(3.19)$ \\
\hline & 0.00 & 0.00 & 0.01 & 0.03 & 0.02 \\
\hline $\mathrm{pde}_{\mathrm{t}}$ & 0.02 & 1.01 & 70.12 & 26.64 & 66.39 \\
\hline & $(1.15)$ & $(4.04)$ & $(5.95)$ & $(7.70)$ & $(8.62)$ \\
\hline & 0.01 & 0.03 & 0.11 & 0.23 & 0.25 \\
\hline $\mathrm{pbe}_{\mathrm{t}}$ & 0.08 & 2.82 & 10.61 & 28.40 & 73.07 \\
\hline & $(1.60)$ & $(3.00)$ & $(3.41)$ & $(3.59)$ & $(3.60)$ \\
\hline & 0.02 & 0.03 & 0.04 & 0.05 & 0.05 \\
\hline
\end{tabular}


Table 6 summarizes the results of the long-horizon forecasting regressions on earnings growth. In this case, our forecasters do capture some components of the small-sized securities and their time-varying earnings growth rate. In particular, $p d e_{t}$ and $p b e_{t}$ are able to provide highly significant coefficients with t-statistics exceeding the value of six in our longer horizons and high $R^{2} S$ of $21 \%$ and $17 \%$ at $h=12$, respectively. In the medium portfolio, forecasting evidence is again richer and is derived by all forecasters, especially $b p_{t}$ which manages to explain $45 \%$ of total variations in this portfolio. The conventional ratios that include information on the index's earnings (that is, $e p_{t}$ and $\left.d e_{t}\right)$ as well as $d p_{t}$ show limited performance with $d e_{t}$ being more capable with big values of t-statistics, even though $R^{2}$ is kept at $10 \%$ till $h=18$. Finally, $p b e_{t}$ proves superior to $p d e_{t}$, even though the performance here is not as impressive as in the case of dividend growth of the medium portfolio.

Additional evidence on the large portfolio though reflect on $p d e_{t}$ 's superiority on capturing variations of largesized securities against a rather milder performance of $b p_{t}, d p_{t}$ and $p b e_{t}$. More specifically, t-statistics reaches the value of 8.62 at $h=24$, while $R^{2}$ becomes $25 \%$. All in all, earnings growth predictability is better explained by $p b e_{t}$ and $p d e_{t}$ in the small portfolio, $b p_{t}$ in the medium and $p d e_{t}$ in the large portfolio. Traditional ratios such as $e p_{t}$ and $b m_{t}$ have been tested for their earnings growth' forecastability (see for instance Lamont, 1998; Pontiff and Schall, 1998) and provided poor outcome for both the DJIA and S\&P's earnings data.

Overall, there are three key findings in this section of the paper. First, return predictability is mainly concentrated in our medium and large portfolios and is better retrieved by $p d e_{t}$ in both cases with $R^{2}$ reaching the values of $35 \%$ and $47 \%$ equivalently. Unlike other studies on this specific data (see for instance, Li, 2009; Bowen et al., 2010), we introduce that our fixed $p d e_{t}$ is a capable explanatory variable of UK return variations. Second, evidence of dividend growth predictability is again observed mostly in the medium and large portfolios. Both $b p_{t}$ and $e p_{t}$ provide highly significant coefficients early on from $h=6$ with rising t-statistics as we increase horizon, similarly to the findings of Wetherilt and Wells (2004) as far as $e p_{t}$ 's forecastability is concerned. Also, $p d e_{t}$ 's explanatory power surpasses the other forecasters in the medium portfolio, while $p b e_{t}$ performs better in the large-sized securities. Third, earnings growth predictability provides more mixed outcomes as we observe predictability evidence in the small portfolio as well, with significant coefficients provided by $p d e_{t}, p b e_{t}$ and $b p_{t}$. In terms of explanatory power, $b p_{t}$ gives an $R^{2}$ of $45 \%$ in the medium portfolio, while variations in the large portfolio are better explained by $p d e_{t}$ with t-statistics exceeding the value of eight. Consequently, some of our findings confirm previous research, but we also provide new indications of the forecastability of certain predictors. Finally, the link with the size criterion that we base our analysis may prove informative to investors interested not only in forecasting but also, in asset pricing and business augmentation.

\section{Conclusion}

In this paper, we have examined the most recent data set of FTSE 100 and analyzed it based on the formation of size portfolios. We have focused on the index's returns, dividend and earnings growth rates and chose four financial ratios, namely $b p_{t}, d p_{t}, e p_{t}$ and $d e_{t}$ as our predictive variables based on their reputation as strong predictors. We also formulate two extra ratios based on the long-run equilibrium relationship of $\left[p_{t}, d_{t}, e_{t}\right]$ and $\left[p_{t}, b_{t}, e_{t}\right]$, namely $p d e_{t}$ and $p b e_{t}$. By allocating all stocks of FTSE 100 into size portfolios according to their market capitalization value, we have not only examined our selected ratios' ability to explain the observed variations in returns and growth rates, but also stress on the presence of any links between size and predictability in-sample.

Our study's main findings can be summarized as following. First, we retrieve evidence that in-sample return predictability is evident in the medium and large-sized portfolios and is better captured by $p d e_{t}$ at $35 \%$ and $47 \%$ equivalently. Second, dividend growth portfolios present strong links with size; particularly, highly significant coefficients are provided by $b p_{t}$ and $e p_{t}$ with rising t-statistic values as we extend the horizon. Similarly, our constructed ratios based on the cointegration relationships act as strong performers too; more specifically, $p d e_{t}$ explains $26 \%$ of the medium portfolio, while $p b e_{t}$ explains $29 \%$ of the large portfolio. Third, in-sample regressions of continuously compounded earnings growth rate show that most predictive benefits are obtained by $d p_{t}$ in the medium portfolio with a $R^{2}$ of $45 \%$. Also, $p d e_{t}$ provides high values of t-statistics both in the small and large portfolios, while $p b e_{t}$ and $b p_{t}$ perform better in the small portfolio.

The encouraging findings of this study suggest that the implementation of further methodologies could lead to even more fruitful evidence. Examining for instance, other macroeconomic variables such as spreads and interest rates and testing the sensitivity of our results on whether we use nominal, excess or real returns are left for future research. We could also attempt to alter our data's frequency into annual so as to address the seasonality effect observed mainly in dividends and earnings (see the discussion in Lamont, 1998; Lettau and Ludvigson, 2005). Additionally, if permitted by data availability, we could extend the time horizon and produce out-of-sample forecasts as well.

An alternative approach would be to study the forecasters' ability before and after Brexit. At present, data is not enough to satisfy such a project but it would be interesting to test the predictive capacity of the examined ratios against an event of this scale. More time may be required to reflect on the true economic effects of the Brexit path, yet still it certainly did not cause an immediate recession as originally speculated, despite the slow turn of the UK's economic growth compared to other major economies (see for instance Born et al., 2017). Perhaps, it is crucial to consider that the majority of the FTSE 100 companies have global presence, thus they generate earnings internationally. Consequently, the value of their assets may rise in different currencies against a weakening pound. This argument is better reflected at the early days of the Brexit Referendum results, that the pound may have fallen 
greatly but overall, the value of the FTSE 100 increased impressively. Also, these companies do diversify and belong to a wide group of sectors. Therefore, some may be severely affected, while others may benefit from these circumstances. Finally, the fact that Brexit has created certain uncertainty in the country's overall outlook is undeniable, however, this may also leave room for investment speculation, particularly for long-term investing plans. We leave this puzzle for future endeavor.

All in all, the relationship between market capitalization value and several forecasters has interesting implications. There are few strings in literature that connect those two traits and could potentially work as a significant parameter to consider in investment decision-making. Our paper may prove informative to investors focused on short-term forecasting and interested in the effects of size in portfolio formation. Further in-depth analysis of this pattern, primarily empirical, can be very beneficial to link the dots between business augmentation and financial forecasting, and provide more entail of the imprint of asset pricing to the real economy.

\section{Acknowledgement}

The present study has been presented at the $10^{\text {th }}$ National Conference of the Financial Engineering and Banking Society, FEBS, held in Athens, Greece, on December 20-21, 2019.

\section{References}

Ang, A. and Bekaert, G., (2007). Stock return predictability: Is it there? Review of Financial Studies, 20 (3), pp. 651-707.

Berk, J. (1995). A critique of size related anomalies. Review of Financial Studies, 8, pp. 275-286.

Black, F., Jensen, M., and Scholes, M. (1972). The Capital Asset Pricing Model: Some Empirical Tests. In Studies in the Theory of Capital Markets, ed. by Jensen, M. New York, Praeger, pp.79-121.

Blume, M. E. (1970). Portfolio Theory: A Step Towards Its Practical Application. Journal of Business, 43, pp. 152-173.

Born, B., Muller, G., Schularick, M., and Sedlacek, P. (2017). The economic consequences of the Brexit vote. Centre for Economic Policy Research (CEPR), Discussion Paper No. 12454.

Bowen, D., Hutchinson, M. C., and O'Sullivan, N. (2010). Predictability Revisited. UK Equity Returns 1965 to 2007. Irish Accounting Review, 17(2), pp. 1-20.

Campbell, J. Y. (1991). A variance decomposition for stock returns. Economic Journal, 101, pp. 157-179.

Campbell, J. Y., and Shiller, R. J. (1998). Stock prices, earnings and expected dividends. Journal of Finance, 43(3), pp. 661-676.

Campbell, J. Y., and Shiller, R. J. (2001). Valuation ratios and the long run stock market outlook: an update. NBER Working Paper No. 8221 (National Bureau of Economic Research).

Campbell, J. Y., and Viceira, L. M. (2002). Strategic asset allocation: Portfolio choice for long-term investors. Oxford University Press. Oxford, UK.

Campbell, J. Y., and Yogo, M. (2006). Efficient tests of stock return predictability. Journal of Financial Economics, 81(1), pp. $27-60$.

Chen, L. (2009). On the reversal of return and dividend growth predictability: A tale of two periods. Journal of Financial Economics, 92(1), pp. 128-151.

Clare, A. D., Smith, P. N., and Thomas, S. H. (1997). UK stock returns and robust tests of mean variance efficiency. Journal of Banking and Finance, 21 (5), pp. 641-660.

Cochrane, J. (1999a). New facts in Finance (Working Paper No. 7169). Retrieved from National Bureau of Economic Research website: https://www.nber.org/papers/w7 169

Cochrane, J. (1999b). Portfolio Advice for a Multifactor World. Economic Perspectives Federal Reserve Bank, 23 (3),pp. 59-78.

Cochrane, J. (2009). Asset Pricing (Revised Edition). Princeton University Press, USA.

Fama, E., F., and French, K., R. (1988). Dividend yields and expected stock returns. Journal of Financial Economics, 22, pp. 3-25.

Fama, E., F., and French, K., R. (1993). Common Risk Factors in the Returns on Stocks and Bonds. Journal of Financial Economics, 33 , pp. 3-56.

Fama, E., F., and MacBeth, J. D., (1973). Risk, Return and Equilibrium: Empirical Tests. Journal of Political Economy, 71, pp. 607636.

Fletcher, J. (2001). An examination of predictable risk and return in UK stock returns. Journal of Economics and Business, 53 (6), pp. 527-546.

Fletcher, J. (2010). Arbitrage and the evaluation of linear factor models in UK stock returns. The Financial Review, 45 (2), pp. $449-$ 468.

Garrett, I., and Priestley, R. (2012). Dividend growth, cash flow and discount rate news. Journal of Financial and Quantitative Analysis, 47 (5), pp. 1003-1028.

Georgiou, C., Grose, C., and Archontakis, F. (2019). Predictable risks and returns: further evidence from the UK stock market. International Journal of Financial Markets and Derivatives, 7 (1), pp. 68-100.

Gill, A., Biger, N., and Tibrewala, R. (2010). Determinants of Dividend Payout Ratios: Evidence from the United States. The Open Business Journal, 3, pp. 8-14.

Johansen, S. (1995). Likelihood-based inference in cointegrated vector autoregressive models. Oxford: Oxford University Press, UK.

Johansen, S., Mosconi, R., and Nielsen, B. (2000). Cointegration analysis in the presence of structural breaks in the deterministic trend. The Econometrics Journal, 3 (2), pp.216-249.

Kothari, S. P., Lewellen, J., and Warner, J. (2006). Stock returns, aggregate earnings surprises and behavioural finance. Journal of Financial Economics, 79, pp. 537-568.

Lamont, O. (1998). Earnings and expected returns. Journal of Finance, 53 (5), pp. 1563-1587.

Lettau, M., and Ludvigson, S. (2001). Consumption, Aggregate Wealth and Expected Stock Returns. Journal of Finance, 56 (3), pp. 815-849.

Lettau, M., and Ludvigson, S. (2005). Expected returns and expected dividend growth. Journal of Financial Economics, 76, pp. 583626. 
Lettau, M., and Van Niewwerburgh (2008). Reconciling the Return Predictability Evidence. Review of Financial Studies, Oxford University Press for Society for Financial Studies, 2 1(4), pp. 1607-1652.

Lewellen, J. (2004). Predicting returns with financial ratios. Journal of Financial Economics, 74(2), pp. $209-235$.

Li, G. (2009). The Horizon Effect of Stock Return Predictability and Model Uncertainty on Portfolio Choice: UK evidence. Working Paper No. E2009/4. Cardiff Business School.

Michou, M., Mouselli, S. and Stark, A. W. (2012). Estimating the Fama and French factors in the UK: An Empirical Review, Working Paper No. 505, Manchester Business School.

Miller, M., H., and Modigliani, F. (1961). Dividend policy, growth and the valuation of shares. The Journal of Business, 34, pp. 411433.

Morelli, D. (2007). Beat, size, book-to-market equity and returns: a study based on UK data. Journal of Multinational Financial Management, 17 (3), pp. 257-272.

Pontiff, J., and Schall, L. D. (1998). Book-to-market ratios as predictors of market returns. Journal of Financial Economics, 49, pp. 141-160.

Sadka, G., and Sadka, R. (2009). Predictability and the earnings-returns relation. Journal of Financial Economics, 94, pp. 87-106.

Shen, P. (2000). The p/e ratio and stock market performance. Economic Review of the Federal Reserve Bank of Kansas City $4^{\text {th }}$ Quarter, 23-36.

Siegel, J. J. (2016). The Shiller CAPE Ratio: A New Look. Financial Analysts Journal, 72 (3), pp.41-50.

Strong, N. and Xu, X. G. (1997). Explaining the cross-section of UK expected stock returns. British Accounting Review, 29 (1), pp. 123.

Teets, W. R., and Wasley, C. E. (1996). Estimating earnings response coefficients: pooled versus firm-specific models. Journal of Accounting and Economics, 21 , pp. 279-295.

Torous, W., Valkanov, R., and Yan, S. (2004). On predicting stock returns with nearly integrated explanatory variables. Journal of Business, 77 (4), pp. 937-966.

Welch, I. and Goyal, A. (2008). A comprehensive look at the empirical performance of equity premium prediction. Review of Financial Studies, 21 (4), pp. 1455-1508.

Wetherilt, A. V. and Wells, S. (2004). Long-horizon equity return predictability: some new evidence from the United Kingdom. Working Paper No.244 (Bank of England). 